\title{
Glucocorticoid Effects on Memory Retrieval Require Concurrent Noradrenergic Activity in the Hippocampus and Basolateral Amygdala
}

\author{
Benno Roozendaal, ${ }^{1}$ Emily L. Hahn, ${ }^{1}$ Sheila V. Nathan, ${ }^{1}$ Dominique J.-F. de Quervain, ${ }^{2}$ and James L. McGaugh ${ }^{1}$ \\ ${ }^{1}$ Center for the Neurobiology of Learning and Memory, Department of Neurobiology and Behavior, University of California, Irvine, California 92697-3800, \\ and ${ }^{2}$ Division of Psychiatry Research, University of Zürich, 8029 Zürich, Switzerland
}

\begin{abstract}
Previous findings indicate that administration of a $\beta$-adrenoceptor antagonist systemically blocks glucocorticoid impairment of memory retrieval. Here, we report that $\beta$-adrenoceptor activation in the hippocampus and the basolateral complex of the amygdala (BLA) is implicated in the impairing effects of glucocorticoids on memory retrieval. The specific glucocorticoid receptor (GR) agonist $11 \beta, 17 \beta$ dihydroxy-6,21-dimethyl-17 $\alpha$-pregna-4,6-trien-20yn-3-one (RU 28362) (15 ng) infused into the hippocampus of male Sprague Dawley rats $60 \mathrm{~min}$ before water maze retention testing, $24 \mathrm{hr}$ after training, impaired probe trial retention performance, as assessed by quadrant search time and initial latency to cross the platform location. Because we found previously that RU 28362 infused into the hippocampus does not affect water maze acquisition or immediate recall, the findings suggest that the GR agonist-induced retention impairment was attributable to a selective influence on long-term memory retrieval. Likewise, systemic injections of the $\beta_{1}$-adrenoceptor partial agonist xamoterol ( 3.0 or $10.0 \mathrm{mg} / \mathrm{kg}$, s.c.) $60 \mathrm{~min}$ before the probe trial dose-dependently impaired retention performance. The $\beta$-adrenoceptor antagonist propranolol $(2.0 \mathrm{mg} / \mathrm{kg})$ administered subcutaneously before retention testing did not affect retention performance alone, but blocked the memory retrieval impairment induced by concurrent intrahippocampal infusions of RU 28362. Pretest infusions of the $\beta_{1}$-adrenoceptor antagonist atenolol into either the hippocampus ( $1.25 \mu \mathrm{g}$ in $\left.0.5 \mu \mathrm{l}\right)$ or the BLA $(0.5 \mu \mathrm{g}$ in $0.2 \mu \mathrm{l})$ also prevented the GR agonist-induced memory retrieval impairment. These findings suggest that glucocorticoids impair retrieval of long-term spatial memory by facilitating noradrenergic mechanisms in the hippocampus, and additionally, that norepinephrine-mediated BLA activity is critical in enabling hippocampal glucocorticoid effects on memory retrieval.
\end{abstract}

Key words: $\beta$-adrenoceptor; corticosterone; emotional arousal; glucocorticoid receptor; norepinephrine; propranolol; atenolol; RU 28362; stress hormone; spatial memory; xamoterol

\section{Introduction}

It is well established that adrenocortical hormones (corticosterone in rats, cortisol in humans) influence memory processes (Lupien and McEwen, 1997; de Kloet et al., 1999; Roozendaal, 2000). Although most studies have focused on acquisition and consolidation, recent findings indicate that glucocorticoids are also involved in stress effects on memory retrieval. Acutely administered corticosterone impairs retrieval of spatial-contextual information when given to rats shortly before memory retention testing (de Quervain et al., 1998; Roozendaal et al., 2004). Additionally, stress exposure or glucocorticoids administered immediately after learning impair short-term (i.e., 30-60 min) retention performance, and this impairment usually subsides after circulating glucocorticoid levels return to baseline (Diamond et

Received May 11, 2004; revised July 26, 2004; accepted July 27, 2004.

This research was supported by United States Public Health Service Grant MH12526 from the National Institute of Mental Health (J.L.M.) and Grant 32-58420.99 from the Swiss National Science Foundation (D.J.-F.d.Q.). We thank Qyana K. Griffith for excellent technical assistance.

Correspondence should be addressed to Dr. Benno Roozendaal, Center for the Neurobiology of Learning and Memory, University of California, Irvine, CA 92697-3800. E-mail: broozend@uci.edu.

DOI:10.1523/JNEUROSCI.2574-04.2004

Copyright $\odot 2004$ Society for Neuroscience $\quad$ 0270-6474/04/248161-09\$15.00/0 al., 1999; Bats et al., 2001; Woodson et al., 2003; Yang et al., 2003; Okuda et al., 2004). Because a glucocorticoid receptor (GR) agonist infused into the hippocampus before retention induces comparable memory retrieval impairment, such findings suggest that glucocorticoid effects on memory retrieval depend, at least in part, on activation of GRs in the hippocampus (Roozendaal et al., 2003).

It is known that glucocorticoids increase norepinephrine turnover in the brain (McEwen, 1987; de Kloet, 1991). Studies investigating long-term memory consolidation indicate that noradrenergic activity within the basolateral complex of the amygdala (BLA) and the hippocampus plays a key role in mediating the modulatory influences of glucocorticoids as well as those of other neuromodulatory systems (Lee et al., 1993; Quirarte et al., 1997; McGaugh, 2000; Roozendaal et al., 2002). Norepinephrine is released in the brain during emotionally arousing conditions (Gold and van Buskirk, 1978; McIntyre et al., 2002), and recent findings suggest that glucocorticoids (and other stress-activated systems) may selectively modulate memory associated with emotionally arousing experiences (Buchanan and Lovallo, 2001; Cahill and Alkire, 2003; Rimmele et al., 2003; Okuda et al., 2004).

Recent findings also suggest that noradrenergic activity may 
be essential in regulating glucocorticoid effects on memory retrieval. A $\beta$-adrenoceptor antagonist administered systemically shortly before retention testing blocks the impairing effects of corticosterone on retrieval of memory for inhibitory avoidance training (Roozendaal et al., 2004). Because the hippocampus is important for mediating glucocorticoid effects on spatial-contextual memory retrieval and receives a dense input of noradrenergic terminals (Schroeter et al., 2000), glucocorticoids may interact with hippocampal noradrenergic mechanisms in influencing memory retrieval. However, $\beta$-adrenoceptors located in the BLA may also be involved, because BLA influences on memory are known to depend critically on noradrenergic neurotransmission (Liang et al., 1995; McIntyre et al., 2002), and we found previously that excitotoxic lesions of the BLA block memory retrieval impairment on a water maze spatial task induced by intrahippocampal infusions of a GR agonist (Roozendaal et al., 2003). The present experiments investigated whether $\beta$-adrenoceptors in the hippocampus and the BLA are involved in regulating glucocorticoid effects on spatial memory retrieval. A $\beta$-adrenoceptor antagonist was administered either systemically or directly into the hippocampus or the BLA shortly before probe trial retention testing in a water maze task to determine whether this noradrenergic blockade prevented memory retrieval impairment induced by concurrent intrahippocampal infusions of the specific GR agonist $11 \beta, 17 \beta$-dihydroxy-6,21-dimethyl- $17 \alpha$ pregna-4,6-trien-20yn-3-one (RU 28362).

\section{Materials and Methods}

Subjects. Male adult Sprague Dawley rats (270-320 gm at time of surgery) from Charles River Breeding Laboratories (Wilmington, MA) were housed individually in a temperature-controlled $\left(22^{\circ} \mathrm{C}\right)$ vivarium room and maintained on a standard $12 \mathrm{hr}$ light/dark cycle (lights on, 7:00 A.M.-7:00 P.M.). Food and water were available ad libitum. Training and testing were performed during the light phase of the cycle between 10:00 A.M. and 2:00 P.M., at the rat nadir of the circadian cycle for corticosterone. All experimental procedures were in compliance with the National Institutes of Health guidelines and were approved by the Institutional Animal Care and Use Committee of the University of California, Irvine.

Surgery. Animals were adapted to the vivarium for at least 1 week before surgery. They were anesthetized with sodium pentobarbital (50 $\mathrm{mg} / \mathrm{kg}$ body weight, i.p.), given atropine sulfate $(0.4 \mathrm{mg} / \mathrm{kg}$, i.p.) to maintain respiration, and were subsequently injected with $3.0 \mathrm{ml}$ of saline to facilitate clearance of these drugs and prevent dehydration. The skull was positioned in a stereotaxic frame (Kopf Instruments, Tujunga, CA) and two stainless steel guide cannulas (11 mm; 23 gauge; Small Parts, Miami Lakes, FL) were implanted with the cannula tips $1.5 \mathrm{~mm}$ above the dorsal hippocampus [coordinates: anteroposterior (AP), $-3.4 \mathrm{~mm}$ from bregma; mediolateral (ML), $\pm 1.7 \mathrm{~mm}$ from midline; dorsoventral (DV), $-2.7 \mathrm{~mm}$ from skull surface, with the incisor bar $3.3 \mathrm{~mm}$ below the interaural line]. For concurrent drug infusions into the BLA, some rats additionally received two guide cannulas ( $15 \mathrm{~mm}$; 23 gauge) implanted $2.0 \mathrm{~mm}$ above the BLA (coordinates: AP, $-2.8 \mathrm{~mm}$; ML, $\pm 5.0 \mathrm{~mm}$; DV, $-6.5 \mathrm{~mm}$ ). The coordinates were based on the atlas of Paxinos and Watson (1997). The cannulas were affixed to the skull with two anchoring screws and dental cement. Stylets (11- or 15-mm-long 00 insect dissection pins) inserted into each cannula to maintain patency were removed only for the infusion of drugs. After surgery, the rats were placed into an incubator until recovery from anesthesia and were then returned to their home cages. They were allowed to recover for a minimum of $7 \mathrm{~d}$ before initiation of training and were handled three times for 1 min each during this recovery period to habituate them to the infusion procedure.

Water maze training and testing. The water maze was a circular, black galvanized tank, $1.83 \mathrm{~m}$ in diameter and $0.58 \mathrm{~m}$ in height, that was filled with water $\left(25^{\circ} \mathrm{C}\right)$ to a depth of $20 \mathrm{~cm}$. A rectangular platform $(20 \times 25$ $\mathrm{cm}$ ) was placed at a fixed location $25 \mathrm{~cm}$ away from the edge of the pool. The platform was submerged $2.5 \mathrm{~cm}$ below the water surface and could not be seen by the rats. The maze was located in a room containing many salient, visual, extra-maze cues.

On each day of training, the rats were transported from the vivarium to the laboratory, and training began $60 \mathrm{~min}$ later. For spatial training, the rats were given four massed trials on each daily session for 3 consecutive days. This relatively small number of trials was chosen such that retention performance of control animals was moderate and drug administration could either enhance or impair performance. Before the first training trial, the rat was placed directly on the submerged platform for $30 \mathrm{sec}$. On each of the trials (i.e., swims), the rat was placed into the tank at one of the four designated starting points in a random order and allowed to find and escape onto the platform. If an animal failed to find the platform within $60 \mathrm{sec}$, it was manually guided to the platform. After mounting the platform, the rat was allowed to remain there for $15 \mathrm{sec}$ and was then placed into a holding cage for $25 \mathrm{sec}$ until the start of the next trial. The time each rat spent to reach the platform was recorded as the escape latency.

Retention of the spatial training was assessed $24 \mathrm{hr}$ after the last training session with a $60 \mathrm{sec}$ free-swim probe trial using a new starting position. The probe trial was videotaped for off-line analysis by an observer blind to drug treatment condition. The parameters measured on the probe trial were time spent in the quadrant containing the platform during training (training quadrant), time spent in the quadrant opposite to the training quadrant (opposite quadrant), initial latency to cross the platform location, and total swim distance. The training and opposite quadrants were equidistant from the starting position used on the probe trial (see Fig. 2C).

Drug treatment. The specific GR agonist RU 28362 (15.0 ng in $0.5 \mu \mathrm{l}$; a gift from Roussel Uclaf, Romainville, France) was infused into the dorsal hippocampus $60 \mathrm{~min}$ before retention testing. Receptor binding studies have shown that this compound has selective and high affinity for GRs (Teutsch et al., 1981). RU 28362 was first dissolved in 100\% ethanol and subsequently diluted with $0.9 \%$ saline to reach its appropriate concentration. The final concentration of ethanol was $0.25 \%$. The vehicle solution contained $0.25 \%$ ethanol in saline only. RU 28362 was kept in a stock solution in $100 \%$ ethanol at $-20^{\circ} \mathrm{C}$. The dose of RU 28362 was based on a previous study indicating memory retrieval impairment after infusion of this dose and volume into the dorsal hippocampus (Roozendaal et al., 2003). Bilateral infusions of RU 28362 or an equivalent volume of vehicle into the dorsal hippocampus were given $60 \mathrm{~min}$ before retention testing by using a 30 gauge injection needle connected to a $10 \mu$ l Hamilton microsyringe (Hamilton, Reno, NV) with polyethylene (PE-20) tubing. The injection needle protruded $1.5 \mathrm{~mm}$ beyond the tip of the cannula, and a $0.5 \mu$ injection volume per hemisphere was infused over a period of $35 \mathrm{sec}$ by an automated syringe pump (Sage Instruments, Boston, $\mathrm{MA})$. The injection needles were retained within the cannulas for an additional $20 \mathrm{sec}$ after drug infusion to maximize diffusion and to prevent backflow of drug into the cannulas.

To examine the influence of $\beta$-adrenoceptor blockade on RU 28362induced spatial memory retrieval impairment, the centrally acting, nonselective $\beta$-adrenoceptor antagonist dl-propranolol hydrochloride (2.0 $\mathrm{mg} / \mathrm{kg}$; Sigma, St. Louis, MO) was dissolved in saline and injected subcutaneously in a volume of $2.0 \mathrm{ml} / \mathrm{kg} 75 \mathrm{~min}$ before retention testing, 15 min before the infusion of either RU 28362 or vehicle into the hippocampus. Additionally, we examined dose-response effects of the $\beta$-adrenoceptor antagonist propranolol and the $\beta_{1}$-adrenoceptor selective partial agonist xamoterol hemifumarate (Tocris Cookson, Ellisville, $\mathrm{MO})$ on probe trial retention performance. For this experiment, propranolol (1.0 or $3.0 \mathrm{mg} / \mathrm{kg}$, s.c.) and xamoterol (3.0 or $10.0 \mathrm{mg} / \mathrm{kg}$, s.c.) were dissolved in saline and administered to intact, nonoperated rats 60 min before probe trial retention testing, $24 \mathrm{hr}$ after completion of training. The $\beta_{1}$-adrenoceptor agonist xamoterol was selected on the basis of a recent study indicating that $\beta_{1}$-adrenoceptors, but not $\beta_{2^{-}}$ adrenoceptors, are involved in memory retrieval (Murchison et al., 2004). The selective $\beta_{1}$-adrenoceptor antagonist atenolol (Sigma) was used for direct infusions into either the hippocampus or the BLA. For bilateral infusions into the hippocampus, atenolol $(1.25 \mu \mathrm{g})$ was coadministered either with the RU 28362 or vehicle solution $60 \mathrm{~min}$ before retention testing. For bilateral infusions into the BLA, atenolol $(0.5 \mu \mathrm{g})$ 

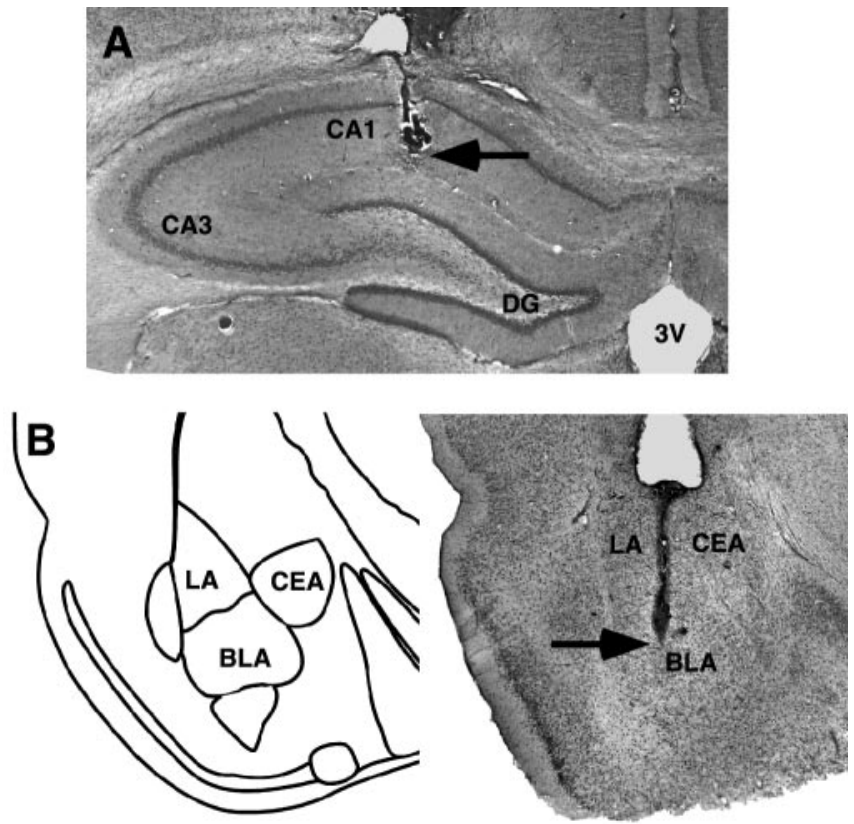

Figure 1. Representative photomicrographs illustrating placement of cannula and needle tip in the dorsal hippocampus $(A)$ and the BLA $(B)$. Arrow points to needle tip. CA1, CA3, Ammon's horn; CEA, central nucleus of the amygdala; DG, dentate gyrus; $L A$, lateral nucleus of the amygdala; $3 \mathrm{~V}$, third ventricle.

was dissolved in saline and infused $60 \mathrm{~min}$ before retention testing, immediately preceding the intrahippocampal infusions of RU 28362 or vehicle. The experimental procedure for intra-BLA infusions of atenolol or saline was similar to that described for infusions into the hippocampus, except that a volume of $0.2 \mu \mathrm{l}$ per hemisphere was infused over a 25 sec period and that the infusion needle protruded $2.0 \mathrm{~mm}$ beyond the cannula tip. The volume used for the intra-BLA infusions was based on findings that drug infusions of this volume into either the BLA or the adjacent central nucleus of the amygdala induce differential effects on memory consolidation (Parent and McGaugh, 1994; Roozendaal and McGaugh, 1997a). All $\beta$-adrenoceptor antagonist and agonist solutions were freshly prepared before each experiment.

Histology. The rats were anesthetized with an overdose of sodium pentobarbital (Sigma) and perfused intracardially with $0.9 \%$ saline followed by $4 \%$ formaldehyde solution $(\mathrm{w} / \mathrm{v})$. After decapitation, the brains were removed and immersed in fresh $4 \%$ formaldehyde. At least $24 \mathrm{hr}$ before sectioning, the brains were transferred to a $20 \%$ sucrose $(\mathrm{w} / \mathrm{v})$ solution in saline for cryoprotection. Coronal slices of $40 \mu \mathrm{m}$ were cut on a freezing microtome, mounted on gelatin-coated slides, and stained with cresyl violet. The sections were examined under a light microscope and the location of injection needle tips in the dorsal hippocampus and the BLA were determined according to the standardized atlas plates of Paxinos and Watson (1997) by an observer blind to drug treatment condition. Rats with injection needle placements outside the hippocampus or the BLA, or with extensive tissue damage at the injection needle tip, were excluded from analysis. Figure $1, A$ and $B$, shows representative photomicrographs of injection needle tip placements in the dorsal hippocampus and the BLA, respectively.

Statistics. Water maze training data were analyzed with a one-way ANOVA with the 12 acquisition trials as repeated measure. Quadrant search times on the probe trial were analyzed with a three-way ANOVA with training and opposite quadrants as repeated measure (two levels) and intrahippocampal RU 28362 treatment (two levels) and $\beta$-adrenoceptor antagonist treatment (two levels) both as betweensubject variables. Platform crossing latencies and total swim distance on the probe trial were analyzed with two-way ANOVAs with intrahippocampal RU 28362 treatment (two levels) and $\beta$-adrenoceptor antagonist treatment (two levels) both as between-subject variables. Paired $t$ tests and Fisher's post hoc tests were used to determine the source of the detected significance in the ANOVAs. A probability level of $<0.05$ was accepted as statistical significance.

\section{Results}

Systemic $\boldsymbol{\beta}$-adrenoceptor antagonist injections block the impairing effect of intrahippocampal GR agonist infusions on water maze retention performance

In a recent study, we reported that systemic administration of the centrally acting $\beta$-adrenoceptor antagonist propranolol blocked corticosterone-induced impairment of memory retrieval for inhibitory avoidance training (Roozendaal et al., 2004). This experiment examined whether systemic injections of propranolol (2.0 $\mathrm{mg} / \mathrm{kg}$, s.c.), administered $75 \mathrm{~min}$ before probe trial retention testing, also blocked memory retrieval impairment on a water maze spatial task induced by intrahippocampal infusions of the specific GR agonist RU 28362 (15 ng) given 60 min before the retention test.

All rats learned to locate the platform position during the $3 \mathrm{~d}$ of training before drug treatment, as indicated by decreasing escape latencies as training progressed $\left(F_{(11,638)}=63.31 ; p<\right.$ 0.0001; data not shown). As shown in Figure 2, systemic injections of propranolol blocked retention performance impairment induced by intrahippocampal infusion of RU 28362. A three-way ANOVA with quadrant as repeated measure revealed no main effects of propranolol $\left(F_{(1,55)}=2.68 ; p=0.11\right)$ or RU 28362 $\left(F_{(1,55)}=1.42 ; p=0.24\right)$ on quadrant search times during the probe trial but did show a significant propranolol $\times$ RU $28362 \times$ quadrant interaction $\left(F_{(1,55)}=4.28 ; p<0.05\right)$ (Fig. $\left.2 A\right)$. Control rats given vehicle infusions into the hippocampus exhibited memory of the platform position during training, as indicated by significantly longer search times in the vicinity of the platform location (i.e., in the training quadrant) than in the opposite quadrant $(p<0.01)$. RU 28362 infused into the hippocampus $60 \mathrm{~min}$ before retention testing decreased time spent in the training quadrant to a chance level ( $p<0.01$, compared with vehicle) and simultaneously increased time spent in the opposite quadrant $(p<0.05)$. Although propranolol administration alone did not affect time spent in the training and opposite quadrants, propranolol blocked the changes in quadrant search time induced by intrahippocampal infusions of RU 28362. Rats given propranolol in combination with RU 28362 spent significantly more time in the training quadrant $(p<0.01)$ and less in the opposite quadrant $(p<0.01)$ than rats given saline injections together with RU 28362. Furthermore, time spent in the training and opposite quadrants by rats treated with propranolol and RU 28362 did not differ significantly from that of either saline- or propranololinjected rats given vehicle infusions into the hippocampus.

The pattern of effects for initial latency to cross the platform location was similar to that for quadrant search times (Fig. 2 B). A two-way ANOVA revealed no propranolol effect $\left(F_{(1,55)}=1.30\right.$; $p=0.26)$ but did find a significant RU 28362 effect $\left(F_{(1,55)}=4.85\right.$; $p<0.05)$ and a significant interaction between both factors $\left(F_{(1,55)}=4.88 ; p<0.05\right)$. Post hoc analysis indicated that RU 28362 infused into the hippocampus increased initial latency to cross the platform location $(p<0.01)$ and that this retention impairment was blocked in rats given systemic injections of propranolol concurrently. Initial crossing latencies of rats given propranolol and RU 28362 were significantly shorter than those of rats given saline together with RU $28362(p<0.05)$ and were equivalent to those of control rats given vehicle into the hippocampus and either saline or propranolol systemically. A twoway ANOVA for total swim distance during the probe trial did not reveal significant RU $28362\left(F_{(1,55)}=0.53\right.$; $\left.p=0.47\right)$, pro- 

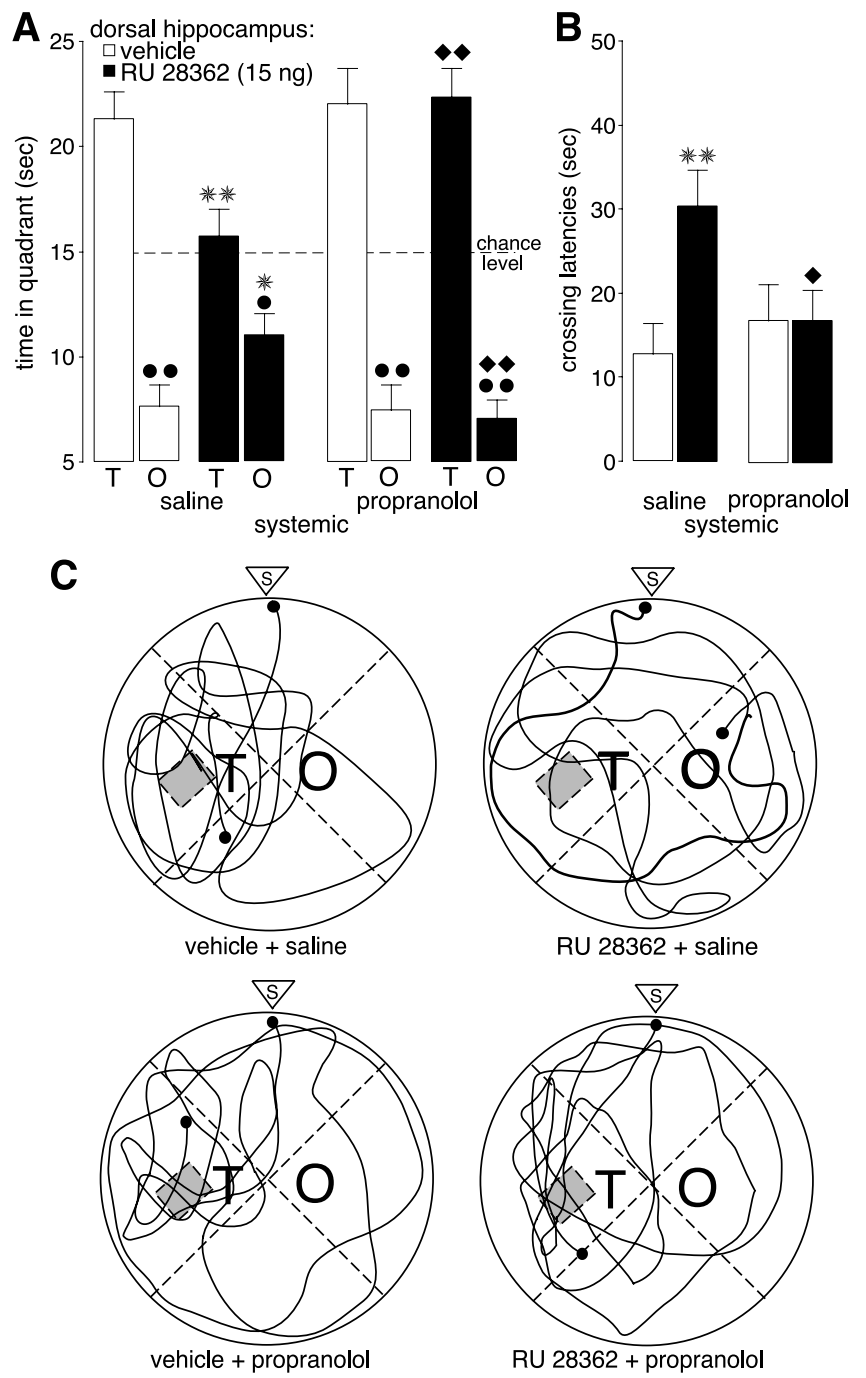

Figure 2. The $\beta$-adrenoceptor antagonist propranolol $(2.0 \mathrm{mg} / \mathrm{kg})$ administered subcutaneously 75 min before retention testing blocked the impairing effects induced by the GR agonist RU 28362 ( $15 \mathrm{ng}$ in $0.5 \mu \mathrm{l}$ ) infused into the hippocampus 60 min before retention testing on probe trial retention performance in a water maze. $A$, Time spent in the training $(T)$ and opposite (0) quadrants (mean + SEM) in seconds during the 60 sec probe trial. $B$, Latencies (mean + SEM) in seconds to cross the platform location. $C$, Representative probe trial swim paths. $S$ indicates start. ${ }^{*} p<0.05,{ }^{* *} p<0.01$ compared with the corresponding vehicle group; $p<$ $0.05, \bullet_{p}<0.01$ compared with the saline-RU 28362 group; ${ }^{\bullet}<0.05,{ }^{\bullet} \bullet_{p}<0.01$ compared with the training quadrant ( $n=13-17$ per group).

pranolol $\left(F_{(1,55)}=0.75 ; p=0.39\right)$, or interaction effects $\left(F_{(1,55)}=\right.$ $0.20 ; p=0.66$; data not shown), indicating that the longer crossing latencies were not caused by any gross changes in swimming speed. Figure $2 C$ shows representative swim paths during the probe trial.

A recent study reported that systemic propranolol administration impaired memory retrieval in rats on water maze spatial and contextual fear conditioning tasks (Murchison et al., 2004). To test whether the absence of a propranolol effect on memory retrieval in our study may have been attributable to a nonoptimal dose, lower or higher doses of propranolol (1.0 or $3.0 \mathrm{mg} / \mathrm{kg}$, s.c.) were administered to intact, nonoperated rats $60 \mathrm{~min}$ before a probe trial, $24 \mathrm{hr}$ after completion of training. Similar to the findings obtained with the $2.0 \mathrm{mg} / \mathrm{kg}$ dose of propranolol, neither the lower nor higher dose of propranolol significantly affected retention performance (Table 1). Therefore, these findings are comparable with those of our recent study using inhibitory avoidance indicating that systemic propran- olol administration blocks glucocorticoid-induced memory retrieval impairment, but do not provide evidence suggesting a general effect of propranolol in impairing memory retrieval (Roozendaal et al., 2004).

Such a dependence of glucocorticoids on $\beta$-adrenoceptor activity in influencing memory retrieval suggests that glucocorticoids impair memory retrieval by facilitating noradrenergic mechanisms. Therefore, we next examined whether $\beta$ adrenoceptor stimulation shortly before retention testing would mimic the effects of the GR agonist on memory retrieval. To test this possibility, the centrally acting $\beta_{1}$-adrenoceptor selective partial agonist xamoterol (3.0 or $10.0 \mathrm{mg} / \mathrm{kg}$, s.c.) was administered to intact, nonoperated rats $60 \mathrm{~min}$ before a probe trial, $24 \mathrm{hr}$ after completion of training. As anticipated, there was a dosedependent reduction in search time in the training quadrant that was significant for $10.0 \mathrm{mg} / \mathrm{kg}$ xamoterol ( $p<0.05$ ). Initial latency to cross the platform location was impaired by both doses of xamoterol (3.0 mg/kg, $p<0.05 ; 10.0 \mathrm{mg} / \mathrm{kg}, p<0.01)$ (Table 1).

Intrahippocampal $\beta$-adrenoceptor antagonist infusions block the effect of intrahippocampal GR agonist infusions on water maze retention impairment

To investigate whether GRs directly interact with $\beta$-adrenoceptors in the hippocampus, this experiment examined the effect on memory retrieval of concurrent infusions of the $\beta_{1}$-adrenoceptor antagonist atenolol and RU 28362 into the hippocampus.

All rats learned to locate the platform position during the $3 \mathrm{~d}$ of training before drug treatment $\left(F_{(11,528)}=70.83 ; p<0.0001\right.$; data not shown). As shown in Figure 3 , the $\beta_{1}$-adrenoceptor antagonist atenolol $(1.25 \mu \mathrm{g})$ administered into the hippocampus $60 \mathrm{~min}$ before retention testing blocked retention performance impairment induced by concurrent infusions of RU 28362. A three-way ANOVA with quadrant as repeated measure revealed no main effects of atenolol $\left(F_{(1,45)}=2.17 ; p=0.15\right)$ or RU $28362\left(F_{(1,45)}=0.26 ; p=0.61\right)$ on quadrant search times during the probe trial (Fig. 3A). However, there was a significant interaction between propranolol, RU 28362, and quadrant $\left(F_{(1,45)}=6.39 ; p<0.05\right)$. Control rats given vehicle infusions into the hippocampus spent significantly more time in the training quadrant than in the opposite quadrant $(p<0.01)$. As was found in the first experiment, RU 28362 infused into the hippocampus 60 min before retention testing decreased time spent in the training quadrant to a chance level ( $p<0.01$, compared with vehicle) and increased time spent in the opposite quadrant $(p<0.05)$. Although pretest administration of atenolol into the hippocampus alone did not affect time spent in either the training and opposite quadrants, atenolol blocked the changes induced by coinfusions of RU 28362 into the hippocampus. Rats given combined infusions of atenolol and RU 28362 spent significantly more time in the training quadrant $(p<0.01)$ and less in the opposite quadrant $(p<0.05)$ than rats given RU 28362 alone and on this measure did not differ significantly from control rats given either vehicle or atenolol infusions into the hippocampus.

A two-way ANOVA for initial latency to cross the platform location (Fig. $3 B$ ) revealed a significant atenolol effect $\left(F_{(1,45)}=\right.$ 4.13; $p<0.05)$, a significant RU 28362 effect $\left(F_{(1,45)}=9.58 ; p<\right.$ $0.01)$, and a significant interaction between both factors $\left(F_{(1,45)}=\right.$ 13.10; $p<0.001)$. RU 28362 infusions into the hippocampus increased initial latency to cross the platform location $(p<0.01)$, and this drug effect was blocked in rats given atenolol concurrently. Initial crossing latencies of rats given atenolol and RU 28362 were significantly shorter than those of rats given RU 28362 alone $(p<0.01)$ and did not differ from those of control 
Table 1. $\boldsymbol{\beta}$-Adrenergic effects on probe trial retention performance in a water maze

\begin{tabular}{lllc}
\hline & Time in training quadrant & Time in opposite quadrant & Platform crossing latency \\
\hline $\begin{array}{l}\text { Saline }{ }^{a}(n=14) \\
\text { Propranolol }^{a}\end{array}$ & $21.7 \pm 1.0^{b}$ & $5.8 \pm 1.1^{b}$ & $8.1 \pm 1.1^{b}$ \\
$1.0 \mathrm{mg} / \mathrm{kg}(n=11)$ & $20.4 \pm 1.1$ & $5.9 \pm 1.2$ & \\
$\quad 3.0 \mathrm{mg} / \mathrm{kg}(n=11)$ & $21.1 \pm 1.7$ & $7.9 \pm 2.3$ & $10.1 \pm 1.7$ \\
Xamoterol & & & $8.4 \pm 1.6$ \\
$3.0 \mathrm{mg} / \mathrm{kg}(n=10)$ & $21.1 \pm 1.9$ & $7.8 \pm 1.0$ & $19.9 \pm 5.8^{*}$ \\
$10.0 \mathrm{mg} / \mathrm{kg}(n=9)$ & $17.4 \pm 1.8^{*}$ & $9.0 \pm 1.4$ & $28.8 \pm 6.6^{* *}$ \\
\hline
\end{tabular}

${ }^{a}$ Drugs were administered subcutaneously in a volume of $2.0 \mathrm{ml} / \mathrm{kg} 60 \mathrm{~min}$ before the 60 sec probe trial.

${ }^{b}$ Values are expressed in seconds (mean $\pm \mathrm{SEM}$ ).

${ }^{*} p<0.05{ }^{* *} p<0.01$ compared with the saline group.
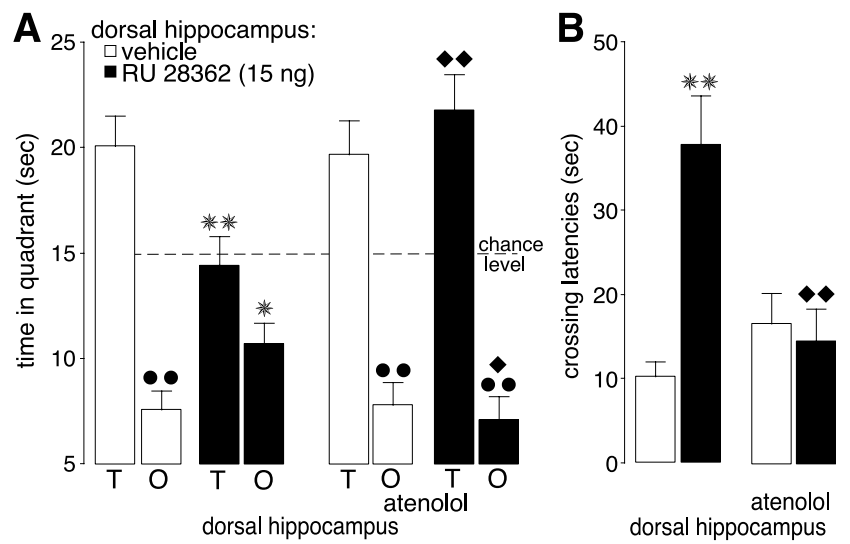

Figure 3. The $\beta_{1}$-adrenoceptor antagonist atenolol ( $1.25 \mu \mathrm{g}$ in $\left.0.5 \mu \mathrm{l}\right)$ administered into the hippocampus $60 \mathrm{~min}$ before retention testing blocked the impairing effects induced by coadministration of the GR agonist RU $28362(15 \mathrm{ng}$ ) on probe trial retention performance in a water maze. $A$, Time spent in the training (T) and opposite (0) quadrants (mean + SEM) in seconds during the $60 \mathrm{sec}$ probe trial. $B$, Latencies (mean + SEM) in seconds to cross the platform location. ${ }^{*} p<0.05,{ }^{* *} p<0.01$ compared with the corresponding vehicle group; $\bullet<0.05, \bullet p<0.01$ compared with the RU 28362 group; ${ }^{\bullet \bullet} p<0.01$ compared with the training quadrant ( $n=11-13$ per group).

rats given either vehicle or atenolol alone. A two-way ANOVA for total swim distance did not reveal significant RU $28362\left(F_{(1,45)}=\right.$ $2.37 ; p=0.13)$, atenolol $\left(F_{(1,45)}=1.88 ; p=0.18\right)$, or interaction effects $\left(F_{(1,45)}=0.17 ; p=0.68\right.$; data not shown $)$.

Intra-BLA infusions of a $\boldsymbol{\beta}$-adrenoceptor antagonist block the effect of intrahippocampal GR agonist infusions on water maze retention impairment

Previous findings have shown that emotionally arousing experiences also induce norepinephrine release in the BLA (Quirarte et al., 1998; McIntyre et al., 2002). Furthermore, because excitotoxic lesions of the BLA block memory retrieval impairment induced by intrahippocampal infusions of the GR agonist (Roozendaal et al., 2003), this experiment examined whether noradrenergic activity in the BLA may be essential in enabling hippocampal glucocorticoid effects on memory retrieval.

All rats learned to locate the platform position during the $3 \mathrm{~d}$ of training before drug treatment $\left(F_{(11,451)}=49.10 ; p<0.0001\right.$; data not shown). Figure 4 shows the effect of intra-BLA infusions of the $\beta$-adrenoceptor antagonist atenolol $(0.5 \mu \mathrm{g})$ on probe trial retention impairment induced by pretest intrahippocampal infusion of RU 28362. A three-way ANOVA with quadrant as repeated measure revealed no main effects of atenolol $\left(F_{(1,38)}=\right.$ $0.45 ; p=0.51)$ or RU $28362\left(F_{(1,38)}=0.25 ; p=0.62\right)$ on quadrant search times during the probe trial but did show a significant interaction between propranolol, RU 28362, and quadrant
$\left(F_{(1,38)}=6.36 ; p<0.05\right)($ Fig. $4 A)$. Control rats given vehicle infusions into the hippocampus spent significantly more time in the training quadrant than in the opposite quadrant $(p<0.01)$. RU 28362 infused into the hippocampus $60 \mathrm{~min}$ before retention testing decreased time spent in the training quadrant to a chance level $(p<0.01$, compared with vehicle) and increased time spent in the opposite quadrant $(p<0.05)$. Although pretest intraBLA infusions of this dose of atenolol did not affect retention performance alone, atenolol blocked the changes in time spent in the training and opposite quadrants induced by RU 28362 infused into the hippocampus. Rats given atenolol and RU 28362 spent significantly more time in the training quadrant $(p<0.01)$ and less in the opposite quadrant $(p<0.01)$ than rats given saline infusions together with RU 28362. Furthermore, time spent in the training and opposite quadrants by rats treated with atenolol and RU 28362 did not differ significantly from that of control rats treated with either saline or atenolol in the BLA and vehicle in the hippocampus.

Initial latencies to cross the platform location of rats in this experiment are presented in Figure $4 B$. A two-way ANOVA revealed significant atenolol $\left(F_{(1,38)}=5.16 ; p<0.05\right)$ and RU 28362 effects $\left(F_{(1,38)}=7.33 ; p<0.05\right)$, as well as a significant interaction between both factors $\left(F_{(1,38)}=8.59\right.$; $\left.p<0.01\right)$. RU 28362 infused into the hippocampus increased initial crossing latencies of rats given saline infusions into the BLA $(p<0.01)$, and this drug effect was blocked in rats given intra-BLA infusions of atenolol. Initial crossing latencies of rats given atenolol and RU 28362 were significantly shorter than those of rats given saline and RU $28362(p<0.01)$. Furthermore, crossing latencies of rats given atenolol and RU 28362 were equivalent to those of rats given vehicle into the hippocampus and either saline or atenolol into the BLA. A two-way ANOVA for total swim distance did not reveal significant RU $28362\left(F_{(1,38)}=0.88 ; p=0.36\right)$, atenolol $\left(F_{(1,38)}=2.24 ; p=0.14\right)$, or interaction effects $\left(F_{(1,38)}=1.05 ; p=\right.$ 0.31 ; data not shown).

\section{Discussion}

These findings indicate that $\beta$-adrenoceptor antagonist administration blocks the impairment of long-term memory retrieval in a water maze spatial task induced by intrahippocampal infusions of a GR agonist. Most importantly, the present findings indicate that $\beta$-adrenoceptors in both the hippocampus and the BLA are implicated in enabling hippocampal GR activation to impair memory retrieval. Because both glucocorticoids and norepinephrine are normally activated by emotional arousal and certain affective disorders, these observations are relevant to understanding the role of emotion and mood in affecting memory retrieval.

The GR agonist RU 28362 administered into the hippocampus $60 \mathrm{~min}$ before probe trial testing significantly impaired retention performance, as assessed by quadrant search time and latency to cross the platform location, but did not affect total swim distance. These findings are consistent with extensive previous evidence indicating that stress exposure or glucocorticoids administered systemically or into the hippocampus shortly before testing on a variety of learning tasks that differ in their behavioral demands, including water maze, inhibitory avoidance, and hole board, induce comparable temporary retention performance impairments (de Quervain et al., 1998; Roozendaal et al., 2003, 

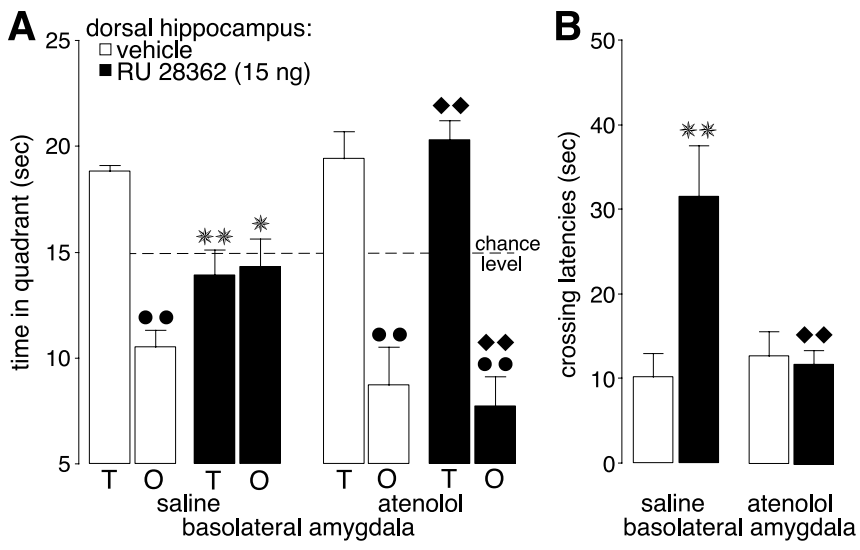

Figure 4. The $\beta_{1}$-adrenoceptor antagonist atenolol ( $0.5 \mu \mathrm{g}$ in $0.2 \mu \mathrm{l}$ ) administered into the BLA 60 min before retention testing blocked the impairing effects induced by the GR agonist RU 28362 ( $15 \mathrm{ng}$ in $0.5 \mu \mathrm{ll}$ ) infused into the hippocampus $60 \mathrm{~min}$ before retention testing on probe trial retention performance in a water maze. $A$, Time spent in the training $(\mathrm{T})$ and opposite $(0)$ quadrants (mean + SEM) in seconds during the 60 sec probe trial. $B$, Latencies (mean + SEM) in seconds to cross the platform location. ${ }^{*} p<0.05,{ }^{* *} p<0.01$ compared with the corresponding vehicle group; ${ }^{\bullet} p<0.01$ compared with the saline-RU 28362 group; $\boldsymbol{\bullet \bullet}_{p}<0.01$ compared with the training quadrant ( $n=9-12$ per group).

2004; Célérier et al., 2004). Because those previous studies also reported that the same treatments administered before training do not affect either water maze acquisition or performance on a probe trial given immediately after acquisition, the findings strongly suggest that the GR agonist-induced retention impairment reflects a direct effect on retrieval of long-term memory. Likewise, stress-level glucocorticoid administration to human subjects impairs delayed, but not immediate, recall on episodic tasks (de Quervain et al., 2000; Wolf et al., 2001; Buss et al., 2004). A selective blockade of mineralocorticoid receptors (MRs) also induces performance deficits in a water maze (Oitzl and de Kloet, 1992). However, because MR antagonist infusions impair both acquisition and retention performance, those findings suggest that MR activation influences response selection, integration of sensory inputs and/or behavioral exploration (Oitzl et al., 1994), effects that differ in several critical ways from those produced by GR agonist infusions.

Extensive cognitive and neurobiological research on animals, healthy human subjects, and amnesic patients indicates that the hippocampus is an important brain region involved in memory retrieval (Hirsch, 1974; Moser and Moser, 1998; Holt and Maren, 1999; Riedel et al., 1999; Schacter and Wagner, 1999; Cabeza and Nyberg, 2000; Eldridge et al., 2000; Squire et al., 2001; Brun et al., 2002; Matus-Amat et al., 2004) and is also a primary target of stress hormones (Reul and de Kloet, 1985). The present findings indicate that glucocorticoid-induced spatial memory retrieval impairment depends on GR activation in the hippocampus. However, because administration of glucocorticoids into the hippocampus can alter glucocorticoid feedback mechanisms (van Haarst et al., 1997; Feldman and Weidenfeld, 1999), local GR activation might potentially affect memory retrieval by an altered corticosterone influence on other brain regions. Our previous finding that this dose of RU 28362 infused into the hippocampus does not alter plasma corticosterone levels (Roozendaal et al., 2003) strongly suggests that GR agonist effects on memory retrieval are attributable directly to influences within the hippocampus. Peripheral administration of corticosterone is known to reduce hippocampal firing rate (Pfaff et al., 1971; Joëls, 2001). Addition- ally, recent findings from an $\mathrm{H}_{2}{ }^{15} \mathrm{O}$-positron-emission tomography study in human subjects indicate that a stress-level dose of cortisone reduces regional blood flow in the right parahippocampal gyrus, an effect that correlates with memory retrieval impairment on episodic tasks (de Quervain et al., 2003).

Stress and glucocorticoids affect a wide range of neurotransmitter systems (de Kloet, 1991). Numerous studies have shown that glucocorticoids are intimately linked with noradrenergic mechanisms and permissively increase noradrenergic neurotransmission in the brain during emotional arousal (McEwen, 1987; Stone et al., 1987; Duman et al., 1989; Roozendaal et al., 2002). There is also evidence of increased sensitivity of the noradrenergic system in stressed individuals (Flugge et al., 1997; Park et al., 2001) and patients with depression or posttraumatic stress disorder (Heninger et al., 1988; Southwick et al., 1999). Our finding that corticosterone administration impairs memory retrieval of an emotionally arousing, but not an emotionally more neutral, version of an object recognition task (Okuda et al., 2004) suggests that glucocorticoid effects on memory retrieval require concurrent noradrenergic activation (Roozendaal et al., 2004). Consistent with this evidence, our current findings indicate that a $\beta$-adrenoceptor antagonist administered systemically or directly into either the hippocampus or the BLA prevents the impairing effect of hippocampal GR activation on memory retrieval. Furthermore, the finding that stimulation of $\beta_{1}$-adrenoceptors with xamoterol induces retention impairment comparable with that seen after GR activation is consistent with the hypothesis that glucocorticoid effects on memory retrieval impairment involve a facilitation of noradrenergic mechanisms in the hippocampus. Several studies indicate that glucocorticoids interact with $\beta$ - and $\alpha_{1}$-adrenoceptors in stimulating cAMP accumulation (Stone et al., 1987; Duman et al., 1989). Also, $\beta_{2}$-adrenoceptor activation potentiates GR transactivation, independent of the CAMP-protein kinase A pathway (Schmidt et al., 2001), and glucocorticoids may increase norepinephrine levels by locally blocking extraneuronal norepinephrine reuptake mechanisms (Grundemann et al., 1998).

Our finding that propranolol administration alone did not affect memory retrieval appears to conflict with that of a recent study reporting that systemic propranolol impaired memory retrieval on a water maze spatial task (Murchison et al., 2004). That study also reported that mutant mice lacking norepinephrineepinephrine show impaired retrieval of certain forms of memory. It is likely that norepinephrine effects on memory retrieval follow an inverted U-shaped dose-response relationship, as previously described for working memory (Arnsten, 2000). Moderately elevated norepinephrine levels such as those induced by mild arousal may facilitate memory retrieval (Sara and Devauges, 1989; Devauges and Sara, 1991; Barros et al., 2001). On the other hand, stress exposure or glucocorticoid administration may further potentiate the noradrenergic response and induce memory retrieval impairment. Additionally, retention-enhancing effects of increased noradrenergic tone, as reported previously, may be caused by influences on mechanisms other than memory retrieval (e.g., nonspecific effects on arousal and attention) (AstonJones et al., 2000).

Recent findings indicate that infusion of noradrenergic agents (as well as drugs affecting several other classes of neurotransmitters) into a variety of brain regions influences memory retrieval (Tuinstra et al., 2000; Barros et al., 2001). Such findings indicate that the hippocampus does not act in isolation in retrieval but, rather, interacts with other brain regions. Our finding that a 
$\beta$-adrenoceptor antagonist infused into the BLA blocks memory retrieval impairment induced by intrahippocampal infusions of a GR agonist concurs with evidence indicating that excitotoxic BLA lesions block hippocampal glucocorticoid effects on memory retrieval (Roozendaal et al., 2003) and suggests that neuronal input from the BLA is essential for enabling hippocampal glucocorticoid effects on memory retrieval. Anatomical evidence is consistent with a role of the BLA in regulating hippocampal processes, because the BLA is known to project extensively to discrete hippocampal subfields (Pikkarainen et al., 1999; Petrovich et al., 2001). Such a modulatory influence of the BLA on memory retrieval involving other brain regions would be consistent with the findings of a recent study investigating the effects of retrieval cues on memory retrieval. Exposure of rats to a relevant retrieval cue before testing enhanced memory retrieval (Gisquet-Verrier et al., 2004) and was accompanied by increased metabolic activity of the amygdala (Boujabit et al., 2003). Because it is thought that the amygdala may not play a direct role in memory retrieval (Barros et al., 2000; Roozendaal et al., 2003), emotional arousal-induced amygdala activity may affect memory retrieval via influences on other brain regions.

Such a role of the BLA in modulating memory retrieval initiated by manipulating GRs in the hippocampus is highly comparable with that suggested by studies investigating its function in mediating drug effects on memory consolidation. Lesions of or $\beta$-adrenoceptor antagonist infusions into the BLA block memory enhancement induced by systemic or intrahippocampal administration of glucocorticoids (Roozendaal and McGaugh, 1996, 1997b; Quirarte et al., 1997; Roozendaal et al., 1999). Electrophysiological studies have provided additional evidence for a role of norepinephrine in BLA-hippocampus interactions. A $\beta$-adrenoceptor antagonist infused into the BLA blocks the effect of electrical stimulation of the perforant path on dentate gyrus population-spike long-term potentiation (Ikegaya et al., 1997). Furthermore, destruction of noradrenergic terminals in the brain produced by the neurotoxin $N$-(2-chloroethyl)- $N$-ethyl-2bromobenzylamine prevents the effect of electrical stimulation of the BLA on hippocampal neuroplasticity (Akirav and RichterLevin, 2002). In a broader theoretical framework, previous studies have indicated that BLA influences on the hippocampus during memory encoding and consolidation reflect the emotional or motivational significance of experiences (Cahill et al., 1996; McGaugh et al., 1996; Kilpatrick and Cahill, 2003; Richter-Levin and Akirav, 2003; Strange et al., 2003; Kensinger and Corkin, 2004). The present findings indicating that the role of BLA noradrenergic activity in regulating emotional arousal effects on hippocampus-dependent cognitive processes is more general and extends to memory retrieval suggest that a common neurobiological substrate may be involved and that stress effects on both cognitive phases may be regulated in a coordinated, albeit opposite, manner (Roozendaal, 2002). Thus, the findings of this study may be relevant to understanding the complex relationship between the multiple effects of stress and glucocorticoids on the brain in influencing different aspects of cognitive function.

\section{References}

Akirav I, Richter-Levin G (2002) Mechanisms of amygdala modulation of hippocampal plasticity. J Neurosci 22:9912-9921.

Arnsten AF (2000) Stress impairs prefrontal cortical function in rats and monkeys: role of dopamine D1 and norepinephrine alpha-1 receptor mechanisms. Prog Brain Res 126:183-192.

Aston-Jones G, Rajkowski J, Cohen J (2000) Locus coeruleus and regulation of behavioral flexibility and attention. Prog Brain Res 126:165-182.

Barros DM, Izquierdo LA, Mello e Souza T, Ardenghi PG, Perreira P, Medina
JH, Izquierdo I (2000) Molecular signalling pathways in the cerebral cortex are required for retrieval of one-trial avoidance learning in rats. Behav Brain Res 114:183-192.

Barros DM, Mello e Souza T, De David T, Choi H, Aguzzoli A, Madche C, Ardenghi P, Medina JH, Izquierdo I (2001) Simultaneous modulation of retrieval by dopaminergic $\mathrm{D}_{1}, \beta$-noradrenergic, serotonergic- $1 \mathrm{~A}$ and cholinergic muscarinic receptors in cortical structures of the rat. Behav Brain Res 124:1-7.

Bats S, Thoumas JL, Lordi B, Tonon MC, Lalonde R, Caston J (2001) The effects of a mild stressor on spontaneous alternation in mice. Behav Brain Res 118:11-15.

Boujabit M, Bontempi B, Destrade C, Gisquet-Verrier P (2003) Exposure to retrieval cues in rats induces changes in regional brain glucose metabolism in the amygdala and other related brain structures. Neurobiol Learn Mem 79:57-71.

Brun VH, Otnass MK, Molden S, Steffenach HA, Witter MP, Moser MB, Moser EJ (2002) Place cells and place recognition maintained by direct entorhinal-hippocampal circuitry. Science 296:2243-2246.

Buchanan TW, Lovallo WR (2001) Enhanced memory for emotional material following stress-level cortisol treatment in humans. Psychoneuroendocrinology 26:307-317.

Buss C, Wolf OT, Witt J, Hellhammer DH (2004) Autobiographic memory impairment following acute cortisol administration. Psychoneuroendocrinology 29:1093-1096.

Cabeza R, Nyberg L (2000) Imaging cognition II: an empirical review of 275 PET and fMRI studies. J Cogn Neurosci 12:1-47.

Cahill L, Alkire MT (2003) Epinephrine enhancement of human memory consolidation: interaction with arousal at encoding. Neurobiol Learn Mem 79:194-198.

Cahill L, Haier RJ, Fallon J, Alkire MT, Tang C, Keator D, Wu J, McGaugh JL (1996) Amygdala activity at encoding correlated with long-term, free recall of emotional information. Proc Natl Acad Sci USA 93:8016-8021.

Célérier A, Piérard C, Rachbauer D, Sarrieau A, Béracochéa D (2004) Contextual and serial discriminations: a new learning paradigm to assess simultaneously the effects of acute stress on retrieval of flexible and stable information in mice. Learn Mem 11:196-204.

de Kloet ER (1991) Brain corticosteroid receptor balance and homeostatic control. Front Neuroendocrinol 12:95-164.

de Kloet ER, Oitzl MS, Joëls M (1999) Stress and cognition: are glucocorticoids good or bad guys? Trends Neurosci 22:422-426.

de Quervain DJ-F, Roozendaal B, McGaugh JL (1998) Stress and glucocorticoids impair retrieval of long-term spatial memory. Nature 394:787-790.

de Quervain DJ-F, Roozendaal B, Nitsch RM, McGaugh JL, Hock C (2000) Acute cortisone administration impairs retrieval of long-term declarative memory in humans. Nat Neurosci 3:313-314.

de Quervain DJ-F, Henke K, Aerni A, Treyer V, McGaugh JL, Berthold T, Nitsch RM, Buck A, Roozendaal B, Hock C (2003) Glucocorticoidinduced impairment of declarative memory retrieval is associated with reduced blood flow in the medial temporal lobe. Eur J Neurosci 17:1296-1302.

Devauges V, Sara SJ (1991) Memory retrieval enhancement by locus coeruleus stimulation: evidence for mediation by beta-receptors. Behav Brain Res 43:93-97.

Diamond DM, Park CR, Heman KL, Rose GM (1999) Exposing rats to a predator impairs spatial working memory in a radial arm water maze. Hippocampus 9:542-552.

Duman RS, Strada SJ, Enna SJ (1989) Glucocorticoid administration increases receptor-mediated and forskolin-stimulated cyclic AMP accumulation in rat brain cerebral cortical slices. Brain Res 477:166-171.

Eldridge LL, Knowlton BJ, Furmanski CS, Bookheimer SY, Engel SA (2000) Remembering episodes: a selective role for the hippocampus during retrieval. Nat Neurosci 3:1149-1152.

Feldman S, Weidenfeld J (1999) Glucocorticoid receptor antagonists in the hippocampus modify the negative feedback following neural stimuli. Brain Res 821:33-37.

Flugge G, Ahrens O, Fuchs E (1997) Beta-adrenoceptors in the tree-shrew brain. II. Time-dependent effects of chronic psychosocial stress on [125I]iodocyanopindolol binding sites. Cell Mol Neurobiol 17:417-432. Gisquet-Verrier P, Botreau F, Venero C, Sandi C (2004) Exposure to retrieval cues improves retention performance and induces changes in 
$\mathrm{ACTH}$ and corticosterone release. Psychoneuroendocrinology 29:529-556.

Gold PE, van Buskirk R (1978) Posttraining brain norepinephrine concentrations: correlation with retention performance of avoidance training and with peripheral epinephrine modulation of memory processing. Behav Biol 25:509-520.

Grundemann D, Schechinger B, Rappold GA, Schöming E (1998) Molecular identification of the corticosterone-sensitive extraneuronal catecholamine transporter. Nat Neurosci 1:349-351.

Heninger GR, Charney DS, Price LH (1988) Noradrenergic and serotonergic receptor system function in panic disorder and depression. Acta Psychiatr Scand [Suppl] 341:138-150.

Hirsch R (1974) The hippocampus and contextual retrieval of information from memory: a theory. Behav Biol 12:421-444.

Holt W, Maren S (1999) Muscimol inactivation of the dorsal hippocampus impairs contextual retrieval of fear memory. J Neurosci 19:9054-9062.

Ikegaya Y, Nakanishi K, Saito H, Abe K (1997) Amygdala $\beta$-noradrenergic influence on hippocampal long-term potentiation in vivo. NeuroReport 8:3143-3146.

Joëls M (2001) Corticosteroid actions in the hippocampus. J Neuroendocrinology 13:657-669.

Kensinger EA, Corkin S (2004) Two routes to emotional memory: distinct neural processes for valence and arousal. Proc Natl Acad Sci USA 101:3310-3315.

Kilpatrick L, Cahill L (2003) Amygdala modulation of parahippocampal and frontal regions during emotionally influenced memory storage. NeuroImage 20:2091-2099.

Lee EH, Lee CP, Wang HI, Lin WR (1993) Hippocampal CRF, NE, and NMDA system interactions in memory processing in the rat. Synapse 14:144-153.

Liang KC, Chen LL, Huang TE (1995) The role of amygdala norepinephrine in memory formation: involvement of memory enhancing effects of peripheral epinephrine. Chin J Physiol 38:81-91.

Lupien SJ, McEwen BS (1997) The acute effects of corticosteroids on cognition: integration of animal and human model studies. Brain Res Rev 24:1-27.

Matus-Amat P, Higgins EA, Barrientos RM, Rudy JW (2004) The role of the dorsal hippocampus in the acquisition and retrieval of context memory representations. J Neurosci 24:2431-2439.

McEwen BS (1987) Glucocorticoid-biogenic amine interaction in relation to mood and behavior. Biochem Pharmacol 36:1755-1763.

McGaugh JL (2000) Memory-a century of consolidation. Science 287:248-251.

McGaugh JL, Cahill L, Roozendaal B (1996) Involvement of the amygdala in memory storage: interaction with other brain systems. Proc Natl Acad Sci USA 93:13508-13514.

McIntyre CK, Hatfield T, McGaugh JL (2002) Norepinephrine levels in the amygdala following inhibitory avoidance training predict retention score. Eur J Neurosci 16:1223-1226.

Moser MB, Moser EJ (1998) Distributed encoding and retrieval of spatial memory in the hippocampus. J Neurosci 18:7535-7542.

Murchison CF, Zhang XY, Zhang WP, Ouyang M, Lee A, Thomas SA (2004) A distinct role for norepinephrine in memory retrieval. Cell 117:131-143.

Oitzl MS, de Kloet ER (1992) Selective corticosteroid antagonists modulate specific aspects of spatial orientation learning. Behav Neurosci 106:62-71.

Oitzl MS, Fluttert M, de Kloet ER (1994) The effect of corticosterone on reactivity to spatial novelty is mediated by central mineralocorticoid receptors. Eur J Neurosci 6:1072-1079.

Okuda S, Roozendaal B, McGaugh JL (2004) Glucocorticoid effects on object recognition memory require training-associated emotional arousal. Proc Natl Acad Sci USA 101:853-858.

Parent MB, McGaugh JL (1994) Posttraining infusion of lidocaine into the amygdala basolateral complex impairs retention of inhibitory avoidance training. Brain Res 661:97-103.

Park CR, Campbell AM, Diamond DM (2001) Chronic psychosocial stress impairs learning and memory and increases sensitivity to yohimbine in adult rats. Biol Psychiatry 50:994-1004.

Paxinos G, Watson C (1997) The rat brain in stereotaxic coordinates, Ed 3. San Diego: Academic.

Petrovich GD, Canteras NS, Swanson LW (2001) Combinatorial amygdalar inputs to hippocampal domains and hypothalamic behavior systems. Brain Res Brain Res Rev 38:247-289.

Pfaff DW, Silva MT, Weiss JM (1971) Telemetred recording of hormone effects on hippocampal neurons. Science 171:394-395.

Pikkarainen M, Rönkkö S, Savander V, Insausti R, Pitkänen A (1999) Projections from the lateral, basal, and accessory basal nuclei of the amygdala to the hippocampal formation in rat. J Comp Neurol 403:229-260.

Quirarte GL, Roozendaal B, McGaugh JL (1997) Glucocorticoid enhancement of memory storage involves noradrenergic activation in the basolateral amygdala. Proc Natl Acad Sci USA 94:14048-14053.

Quirarte GL, Galvez R, Roozendaal B, McGaugh JL (1998) Norepinephrine release in the amygdala in response to footshock and opioid peptidergic drugs. Brain Res 808:134-140.

Reul JM, de Kloet ER (1985) Two receptor systems for corticosterone in the rat brain: microdistribution and differential occupation. Endocrinology 117:2505-2512.

Richter-Levin G, Akirav I (2003) Emotional tagging of memory formation-in the search for neural mechanisms. Brain Res Brain Res Rev 43:247-256.

Riedel G, Micheau J, Lam AG, Roloff E, Martin SJ, Bridge H, de Hoz L, Poeschel B, McCulloch J, Morris RG (1999) Reversible neural inactivation reveals hippocampal participation in several memory processes. Nat Neurosci 2:898-905.

Rimmele U, Domes G, Mathiak K, Hautzinger M (2003) Cortisol has different effects on human memory for emotional and neutral stimuli. NeuroReport 14:2485-2488.

Roozendaal B (2000) Glucocorticoids and the regulation of memory consolidation. Psychoneuroendocrinology 25:213-238.

Roozendaal B (2002) Stress and memory: opposing effects of glucocorticoids on memory consolidation and memory retrieval. Neurobiol Learn Mem 78:578-595.

Roozendaal B, McGaugh JL (1996) Amygdaloid nuclei lesions differentially affect glucocorticoid-induced memory enhancement in an inhibitory avoidance task. Neurobiol Learn Mem 65:1-8.

Roozendaal B, McGaugh JL (1997a) Glucocorticoid receptor agonist and antagonist administration into the basolateral but not central amygdala modulates memory storage. Neurobiol Learn Mem 67:176-179.

Roozendaal B, McGaugh JL (1997b) Basolateral amygdala lesions block the memory-enhancing effect of glucocorticoid administration in the dorsal hippocampus of rats. Eur J Neurosci 9:76-83.

Roozendaal B, Nguyen BT, Power AE, McGaugh JL (1999) Basolateral amygdala noradrenergic influence enables enhancement of memory consolidation induced by hippocampal glucocorticoid receptor activation. Proc Natl Acad Sci USA 96:11642-11647.

Roozendaal B, Quirarte GL, McGaugh JL (2002) Glucocorticoids interact with the basolateral amygdala $\beta$-adrenoceptor-cAMP/PKA system in influencing memory consolidation. Eur J Neurosci 15:553-560.

Roozendaal B, Griffith QK, Buranday J, de Quervain DJ-F, McGaugh JL (2003) The hippocampus mediates glucocorticoid-induced impairment of spatial memory retrieval: dependence on the basolateral amygdala. Proc Natl Acad Sci USA 100:1328-1333.

Roozendaal B, de Quervain DJ-F, Schelling G, McGaugh JL (2004) A systemically administered $\beta$-adrenoceptor antagonist blocks corticosteroneinduced impairment of contextual memory retrieval in rats. Neurobiol Learn Mem 81:150-154.

Sara SJ, Devauges V (1989) Idazoxan, an $\alpha-2$ antagonist, facilitates memory retrieval in the rat. Behav Neural Biol 51:401-411.

Schacter DL, Wagner AD (1999) Medial temporal lobe activations in fMRI and PET studies of episodic encoding and retrieval. Hippocampus 9:7-24.

Schmidt P, Holsboer F, Spengler D (2001) Beta(2)-adrenergic receptors potentiate glucocorticoid receptor transactivation via $G$ protein beta gamma-subunits and the phosphoinositide 3-kinase pathway. Mol Endocrinol 15:553-564.

Schroeter S, Apparsundaram S, Wiley RG, Milner LH, Sesack SR, Blakely RD (2000) Immunolocalization of the cocaine- and antidepressant sensitive I-norepinephrine transporter. J Comp Neurol 420:211-232.

Southwick SM, Morgan CA III, Charney DS, High JR (1999) Yohimbine use in a natural setting: effects of posttraumatic stress disorder. Biol Psychiatry 46:442-444.

Squire LR, Clark RE, Knowlton BJ (2001) Retrograde amnesia. Hippocampus 11:50-56.

Stone EA, McEwen BS, Herrera AS, Carr KD (1987) Regulation of $\alpha$ and $\beta$ 
components of noradrenergic cAMP response in cortical slices. Eur J Pharmacol 141:347-356.

Strange BA, Hurlemann R, Dolan RJ (2003) An emotion-induced retrograde amnesia in humans is amygdala- and $\beta$-adrenergic-dependent. Proc Natl Acad Sci USA 100:13626-13631.

Teutsch G, Costerousse G, Deraedt R, Benzoni J, Fortin M, Philibert D (1981) 17alpha-alkynyl-11beta, 17-dihydroxyandrostane derivates: a new class of potent glucocorticoids. Steroids 38:651-665.

Tuinstra T, Verheij M, Willemen A, Iking J, Heeren DJ, Cools AR (2000) Retrieval of spatial information in Nijmegen high and low responders: involvement of beta-adrenergic mechanisms in the nucleus accumbens. Behav Neurosci 114:1088-1095.

van Haarst AD, Oitzl MS, de Kloet ER (1997) Facilitation of feedback inhi- bition through blockade of glucocorticoid receptors in the hippocampus. Neurochem Res 22:1323-1328.

WolfOT, Convit A, McHugh PF, Kandil E, Thorn EL, De Santi S, McEwen BS, de Leon MJ (2001) Cortisol differentially affects memory in young and elderly men. Behav Neurosci 115:1002-1011.

Woodson JC, Macintosh D, Fleshner M, Diamond DM (2003) Emotioninduced amnesia in rats: working memory-specific impairment, corticosterone-memory correlation, and fear versus arousal effects on memory. Learn Mem 10:326-336.

Yang Y, Cao J, Xiong W, Zhang J, Zhou Q, Wei H, Liang C, Deng J, Li T, Yang S, Xu L (2003) Both stress experience and age determine the impairment or enhancement effect of stress on spatial memory retrieval. J Endocrinol 178:45-54. 